\title{
Confirmation of thermal dose as a predictor of local control in cervical carcinoma patients treated with state-of-the-art radiation therapy and hyperthermia
}

\author{
Citation for published version (APA): \\ Kroesen, M., Mulder, H. T., van Holthe, J. M. L., Aangeenbrug, A. A., Mens, J. W. M., van Doorn, H. C., \\ Paulides, M. M., Oomen-de Hoop, E., Vernhout, R. M., Lutgens, L. C., van Rhoon, G. C., \& Franckena, M. \\ (2019). Confirmation of thermal dose as a predictor of local control in cervical carcinoma patients treated with \\ state-of-the-art radiation therapy and hyperthermia. Radiotherapy and Oncology, 140, 150-158. \\ https://doi.org/10.1016/j.radonc.2019.06.021
}

\section{Document license: \\ TAVERNE}

DOI:

10.1016/j.radonc.2019.06.021

Document status and date:

Published: 01/11/2019

\section{Document Version:}

Publisher's PDF, also known as Version of Record (includes final page, issue and volume numbers)

\section{Please check the document version of this publication:}

- A submitted manuscript is the version of the article upon submission and before peer-review. There can be important differences between the submitted version and the official published version of record. People interested in the research are advised to contact the author for the final version of the publication, or visit the $\mathrm{DOI}$ to the publisher's website.

- The final author version and the galley proof are versions of the publication after peer review.

- The final published version features the final layout of the paper including the volume, issue and page numbers.

Link to publication

\footnotetext{
General rights

- You may freely distribute the URL identifying the publication in the public portal. follow below link for the End User Agreement:

www.tue.nl/taverne

\section{Take down policy}

If you believe that this document breaches copyright please contact us at:

openaccess@tue.nl

providing details and we will investigate your claim.
}

Copyright and moral rights for the publications made accessible in the public portal are retained by the authors and/or other copyright owners and it is a condition of accessing publications that users recognise and abide by the legal requirements associated with these rights.

- Users may download and print one copy of any publication from the public portal for the purpose of private study or research.

- You may not further distribute the material or use it for any profit-making activity or commercial gain

If the publication is distributed under the terms of Article $25 \mathrm{fa}$ of the Dutch Copyright Act, indicated by the "Taverne" license above, please 
Original Article

\title{
Confirmation of thermal dose as a predictor of local control in cervical carcinoma patients treated with state-of-the-art radiation therapy and hyperthermia
}

\author{
Michiel Kroesen ${ }^{a}$, Hendrik T. Mulder ${ }^{a}$, Jeanette M.L. van Holthe ${ }^{\mathrm{a}}$, Aleida A. Aangeenbrug ${ }^{\mathrm{a}}$, \\ Jan Willem M. Mens ${ }^{\mathrm{a}}$, Helena C. van Doorn ${ }^{\mathrm{b}}$, Margarethus M. Paulides ${ }^{\mathrm{a}, \mathrm{c}}$, Esther Oomen-de Hoop ${ }^{\mathrm{a}}$, \\ Rene M. Vernhout ${ }^{\mathrm{a}}$, Ludy C. Lutgens ${ }^{\mathrm{d}}$, Gerard C. van Rhoon ${ }^{\mathrm{a}}$, Martine Franckena ${ }^{\mathrm{a}, *}$

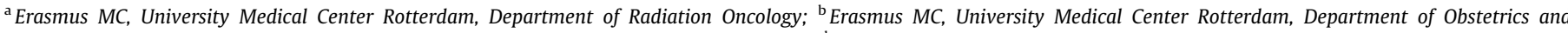

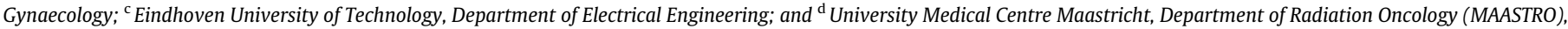 \\ Maastricht, The Netherlands
}

\section{A R T I C L E I N F O}

\section{Article history:}

Received 8 November 2018

Received in revised form 13 June 2019

Accepted 14 June 2019

\section{Keywords:}

Hyperthermia

Cervical cancer

Treatment outcome

Thermal dose

Trise

CEM43T90

Image guided brachytherapy

\begin{abstract}
A B S T R A C T
Background: Addition of deep hyperthermia results in improved local control (LC) and overall survival (OS) compared to radiotherapy alone in patients with cervical carcinoma. Previously, we showed that the thermal dose of hyperthermia significantly correlates with LC and disease specific survival (DSS). Over the last decade, new radiation techniques were introduced resulting in improved LC.

Aim: To validate the effect of thermal dose in a more recent cohort of patients treated with modern radiotherapy techniques, including image guided brachytherapy (IGBT).

Methods: We analyzed primary cervical carcinoma patients treated with a combination of radiotherapy and deep hyperthermia between 2005 and 2016 at our institute. Data on patient, tumor and treatment were collected including the thermal dose parameters TRISE and CEM43T90. Follow-up data on LC, disease free survival, DSS, OS as well as late toxicity data were collected. Data were analyzed using the Cox proportional hazard and Kaplan-Meier analyses.

Results: 227 patients were included. In multivariate analysis, histology, FIGO stage, lymphadenopathy, TRISE, CEM43T90 and IGBT had a significant effect on LC. In the patients treated with IGBT, the thermal dose parameter TRISE remained to have a significant effect on LC in univariate analysis.

Conclusions: The positive association between thermal dose and clinical outcome is replicated in an independent, recent cohort of cervical carcinoma patients. Importantly, in patients receiving IGBT, the effect of thermal dose on clinical outcome is still observed.
\end{abstract}

(C) 2019 Elsevier B.V. All rights reserved. Radiotherapy and Oncology xxx (2019) xxx-xxx
Cervical carcinoma is the sixth most common cancer in woman in The Netherlands and the fourth most common cancer in woman worldwide [1]. Radiotherapy remains the cornerstone of treatment for women with a locally advanced cervical carcinoma [2]. Chemotherapy and hyperthermia are effective sensitizers of radiotherapy in these patients, resulting in improved overall survival (OS). Addition of hyperthermia to radiotherapy results in local control (LC) and OS rates comparable to chemoradiotherapy in patients with large FIGO IIB or higher FIGO stage tumors [2-8].

Hyperthermia, defined as an elevation of tumor temperature in the range of $40-44{ }^{\circ} \mathrm{C}$, is a potent sensitizer of radiation therapy $[9,10]$. The thermal enhancement of hyperthermia depends on the thermal dose, which is the net result of the temperature rise

\footnotetext{
* Corresponding author.

E-mail address: m.franckena@erasmusmc.nl (M. Franckena).
}

in the tumor and the duration of the heating [11]. The achieved thermal dose in a particular patient is influenced by several factors including patient condition, patient comfort and technical possibilities to steer the energy deposition. Thermal dose parameters considered to be related with treatment outcome are: CEM43T90 (cumulative equivalent minutes of T90 above $43^{\circ} \mathrm{C}$ ) and our linearized version TRISE $[11,12]$. We have previously shown a dose dependent effect of CEM43T90 and TRISE on LC and OS in 420 patients treated with thermoradiotherapy between May 1990 and July 2005 [11].

In the last decade several improvements in the treatment of cervical carcinoma patients have taken place, both globally as well as in our institute. At our institute, the more conformal radiotherapy techniques intensity modulated radiotherapy (IMRT) and volumetric arc therapy (VMAT) were introduced, along with a plan-of the-day protocol [13]. These techniques allow adequate target 
coverage, while reducing dose to the adjacent organs [13,14]. Second, introduction of image-MRI-guided brachytherapy (IGBT) results in more conformal and higher dose to the tumor, leading to improved LC, disease specific survival (DSS) and OS with acceptable toxicity [15-20]. IGBT was introduced at our institute in 2012.

Besides improvements in radiotherapy techniques, technological developments in hyperthermia delivery techniques have been implemented. In 2011 SAR-based hyperthermia treatment planning (HTP) guided steering was introduced for all deep hyperthermia patients at our institute [21]. In a cross over study we showed that with HTP guided steering, the thermal dose achieved was comparable to our empirical steering protocol. Further, HTP guided steering holds the promise to predict treatment quality and of patient-specific optimization and real-time complaint alleviation [22].

We are not aware of any studies confirming our previously found association between thermal dose and clinical outcome in cervical carcinoma patients. In addition, the effect of thermal dose in patients treated with IGBT, leading to improved LC, is unknown. The aim of this study was to determine the effect of thermal dose on clinical outcome in an independent, more recent cohort. In addition, we specifically analyzed the effect of thermal dose in the patients treated with state-of-the-art IGBT.

\section{Methods}

\section{Patient population}

The research protocol for this investigation was approved by the medical ethics committee of Erasmus MC, University Medical Center Rotterdam (MEC-2018-1081). Patients included were diagnosed with primary cervical cancer and treated with curative intent using thermoradiotherapy at our institute between July 2005 and December 2016. Excluded were patients receiving concurrent chemotherapy, fewer than four of the five intended hyperthermia sessions and patients receiving radiotherapy at other institutes because of a lack of data on follow-up. All patients had a histologically confirmed cervical carcinoma and were staged by the International Federation of Gynaecology and Obstetrics (FIGO) clinical staging system, including investigation under general anesthesia with cystoscopy and lymph node staging using CT and/or MRI and/or PET-CT.

Indications for primary thermoradiotherapy at the Erasmus MC Cancer Institute are locally advanced tumors: 'lateral' FIGO IIB ( $>50 \%$ parametrial invasion), IIIA, IIIB and IVA. In addition, patients with inoperable tumors and a contra-indication for, or refusing cisplatin-based chemotherapy are also treated with thermoradiotherapy. Patients with a local tumor equal to or larger than $6 \mathrm{~cm}$ and/or large para-aortic $(>1 \mathrm{~cm})$ or iliac $(>2 \mathrm{~cm})$ lymphadenopathy were treated upfront with induction chemotherapy, followed by standard thermoradiotherapy [23]. Induction chemotherapy consists of 6-weekly cycles of cisplatin/taxol chemotherapy, with clinical assessment after 3 and 6 cycles.

\section{Radiotherapy treatment}

Radiotherapy consisted of daily external beam radiotherapy (EBRT) $23 \times 2$ Gy for pelvic fields or $28 \times 1.8 \mathrm{~Gy}$ if the para-aortal region was included. EBRT was delivered using 3D conformal techniques until 2011, after which intensity modulated radiotherapy (IMRT) was introduced. From 2014 onwards volumetric arc therapy (VMAT) was the preferred technique, because of even better conformity and faster treatment times. From 2011 onwards a plan-of-the day protocol was introduced to adapt the plan to the position of the uterus, thereby decreasing dose to bowel and bladder [13]. A brachytherapy boost was delivered using a high-dose rate iridium source using 2D planning to point $A$, with a dose of $2 \times 8,5 \mathrm{~Gy}$. From the end of 2012 onwards, image (MRI) guided brachytherapy (IGBT) was applied with a combined interstitial and intracavitary approach, delivering 3 or 4 fractions of $7 \mathrm{~Gy}$ or more to the high-risk CTV [20].

\section{Hyperthermia treatment}

Hyperthermia (HT) was delivered after radiotherapy, a total of five times during the 5-6 weeks of EBRT. The BSD-2000 system (Pyrexar Medical Corporation, Salt Lake City, Utah, USA) was used for all HT treatments, with the Sigma-60 or Sigma-Eye applicator selection depending on the patients' size. Intraluminal thermometry was performed by placing thermometers in rectum, bladder and vagina for all patients. Until July 2012 thermometry was performed by using Bowman probes (Pyrexar Medical Corporation, Salt Lake City, Utah, USA) combined with thermal mapping every 5 min during treatment with a step size of $1 \mathrm{~cm}$ and a maximum length of $14 \mathrm{~cm}$. Hereafter temperature measurement was continuous using multi-sensor fiber optic temperature probes (FISO Technologies Inc., Québec, QC, Canada, 4-8 sensors with a distance between sensors of $2 \mathrm{~cm}$ ). Both systems fulfill the quality assurance guidelines of European Society for Hyperthermic Oncology, accuracy $\pm 0.2{ }^{\circ} \mathrm{C}[24,25]$. The 90 minutes scheduled treatment time consists of a 30 min warm up period to intraluminal temperatures of $\geq 40{ }^{\circ} \mathrm{C}$. Then treatment was continued for $60 \mathrm{~min}$ aiming for maximum intraluminal temperatures depending on patient tolerance.

\section{Collection patient and follow-up data}

The following patient characteristics were extracted from the patients' files: age at diagnosis, histology, FIGO stage and lymph node status. Local FIGO stage was noted except for 6 patients presenting with limited distant metastases-but treated with curative intent-which were recorded as FIGO IVB. Radiotherapy and HT treatment characteristics were extracted from treatment planning and other recording systems.

Pelvic recurrence, distant recurrence, survival status, date and cause of death, as well as late toxicity data were extracted and/or retrieved from patient records, referring hospitals, general physicians and the civil registry. Late toxicity, occurring and/or persisting after 6 months following treatment, was scored according to CTCAE v4.0 [26]. Only high-grade (equal or higher than grade 3) toxicities were extracted, as these events are clinically most relevant and most reliably extracted retrospectively.

\section{Hyperthermia quality parameters}

Hyperthermia treatment characteristics extracted were number of hyperthermia treatments, CEM43T90, TRISE and treatment duration. The CEM43T90 is the mean cumulative equivalent minutes of T90 (temperature reached in at least $90 \%$ of measurement locations) at $43{ }^{\circ} \mathrm{C}$ [12]. TRISE is a thermal dose parameter based on ALT50 (temperature exceeded by $50 \%$ of all measurement sites) and duration of heating. CEM43T90 and TRISE were calculated for all patients, as described previously by our group in detail [27]. Temperatures during treatment were measured intraluminal, but are considered representative for tumor temperatures [28].

\section{Statistical analysis}

LC, disease free survival (DFS), DSS and OS were calculated from start date of radiation therapy until the event. LC was noted as 'failed' when a physician diagnosed a local recurrence of cervical carcinoma either clinically or with imaging (CT/MRI). Pathological 
confirmation of a recurrence was not required as clinical diagnosis is evident and biopsies are only taken in case of doubt. For DFS, an event was defined as the occurrence of either local or distant recurrence. Patients were censored for local or distant control after the last visit of any physician specifically examining for recurrent disease. For DSS and OS, patients without an event were censored on the day the civil registry was consulted. LC, DFS and DSS were analyzed using the Kaplan-Meier method and statistical differences between groups were determined using the log-rank test. A $p$ value of $\leq 0.05$ was considered statistically significant. Differences in continuous factors between groups were analyzed using the Mann-Whitney $U$ test. Differences in categorical factors between groups were analyzed using the Chi-Square of Fisher's exact test. Hazard ratio (HR) and 95\% confidence interval (CI) for various covariates were obtained by univariate Cox proportional hazards analyses. No correction for multiple testing is applied as our primary aim was to validate our previous findings on the 2 thermal dose parameters TRISE and CEM43T90. For categorical values, all categories were compared to the lowest category. Covariates were taken into multivariable analysis based on clinical experience and a $p$-value $\leq 0.20$ in univariate analysis. A backward selection procedure was applied with $p<0.05$ as a threshold to find the combination of factors that have independent prognostic value. All analyses were performed using IBM SPSS statistics version 24.0 software package (SPSS Inc., Chicago, IL, USA).

\section{Results}

\section{General characteristics of the cohort}

In total, 227 patients were included in the study. Characteristics of the total cohort are listed in Table 1; detailed information on the distribution over the treatment protocols is provided in the diagram in Fig. 1. Median follow-up time for local and distant recurrence was 52 months (interquartile range (IQR) 3064 months). Median follow-up time for survival was 82 months (IQR 45-110 months). For the entire cohort, 5-y LC was $72.7 \%$, $5-\mathrm{y}$ DFS was $57.9 \%, 12-\mathrm{y}$ DSS was $60.0 \%$ and $12-\mathrm{y}$ OS was $40.1 \%$. There were 55 cases with a local recurrence out of the 90 cases with any recurrence. Furthermore, there were 74 disease specific deaths out of 107 total deaths. Temperature data were system-lost in 23 cases, hence for thermal dose 204 cases were analyzed.

\section{Univariate and multivariate Cox proportional hazard analyses}

Using univariate Cox proportional hazard analysis, the influence of known prognostic factors and thermal dose on LC, DFS, DSS and OS was analyzed. Histology (squamous cell vs. adenocarcinoma; HR 0.38; 95\% CI 0.20-0.74), FIGO stage (IIIA + IIIB vs. IB; HR 3.87; 95\% CI 1.45-10.33), CEM43T90 (HR 0.86; 95\% CI 0.760.98 ), TRISE (HR 0.54; $95 \%$ CI $0.35-0.81$ ) and IGBT (HR 0.46; $95 \%$ CI $0.22-0.95$ ) showed a significant effect on LC. FIGO stage and IGBT also had a significant effect on DSS (Table 2). To determine the relative contribution of factors multivariate Cox analyses were performed. As CEM43T90 and TRISE are both indicators of thermal dose, these factors were introduced separately into the analysis. Histology (squamous cell vs. adenocarcinoma; HR 0.33; 95\% CI 0.16-0.69), FIGO stage (IIIA + IIIB vs. IB; HR 4.04; 95\% CI 1.47-11.14), Lymphadenopathy (negative vs. iliac; HR 2.75; 95\% CI 1.37-5.53), TRISE (HR 0.43; 95\% CI $0.28-$ 0.68 ), CEM43T90 (HR 0.83; 95\% CI 0.72-0.96) and IGBT (HR $0.40 ; 95 \%$ CI $0.19-0.84$ ) had a significant effect on LC (Table 2). FIGO stage and IGBT also had an independent effect on DSS (Table 2).
Table 1

General characteristics of the cohort.

\begin{tabular}{|c|c|c|}
\hline Characteristic & Categories & Value \\
\hline \multicolumn{3}{|l|}{ Patient/tumor characteristics } \\
\hline \multirow[t]{2}{*}{ Age (years) } & & Median \\
\hline & & 54.0 (IQR 43.0-68.8) \\
\hline \multirow[t]{3}{*}{ Histology } & Adeno & $26(11.5 \%)$ \\
\hline & SCC & $189(83.3 \%)$ \\
\hline & Other & $12(5.3 \%)$ \\
\hline \multirow[t]{7}{*}{ FIGO stage } & IB & $32(14.1 \%)$ \\
\hline & IIA & $10(4.4 \%)$ \\
\hline & IIB & $108(47.6 \%)$ \\
\hline & IIIA & $11(4.8 \%)$ \\
\hline & IIIB & $42(18.5 \%)$ \\
\hline & IVA & $18(7.9 \%)$ \\
\hline & IVB & $6(2.6 \%)$ \\
\hline \multirow[t]{3}{*}{ Tumor $\geq 6 \mathrm{~cm}$} & No & $114(50.2 \%)$ \\
\hline & Yes & $95(41.9 \%)$ \\
\hline & Unknown & $18(7.9 \%)$ \\
\hline \multirow[t]{4}{*}{ Lymph nodes } & Negative & $91(40.1 \%)$ \\
\hline & Iliac & $92(40.5 \%)$ \\
\hline & PAO & $43(18.9 \%)$ \\
\hline & Missing & $1(0.4 \%)$ \\
\hline \multirow[t]{2}{*}{ Induction chemotherapy } & No & $140(61.7 \%)$ \\
\hline & Yes & $87(38.3 \%)$ \\
\hline \multicolumn{3}{|l|}{ Radiation therapy characteristics } \\
\hline \multirow[t]{3}{*}{ Radiation technique } & 3DCRT & $135(59.5 \%)$ \\
\hline & IMRT & $50(22.0 \%)$ \\
\hline & VMAT & $42(18.5 \%)$ \\
\hline \multirow[t]{2}{*}{ Radiation field } & Pelvic & $169(74.4 \%)$ \\
\hline & Pelvic + PAO & $58(25.6 \%)$ \\
\hline \multirow[t]{3}{*}{ Brachytherapy use } & No & $18(7.9 \%)$ \\
\hline & Yes & $208(91.6 \%)$ \\
\hline & Missing & $1(0.4 \%)$ \\
\hline \multirow[t]{2}{*}{ MRI-guided BT use } & No & $161(70.9 \%)$ \\
\hline & Yes & $66(29.1 \%)$ \\
\hline \multicolumn{3}{|c|}{ Hyperthermia treatment characteristics } \\
\hline \multirow[t]{4}{*}{$\mathrm{N}$ of treatments } & 2 & $3(1.3 \%)$ \\
\hline & 3 & $5(2.2 \%)$ \\
\hline & 4 & $13(5.7 \%)$ \\
\hline & 5 & $206(90.7 \%)$ \\
\hline \multirow[t]{3}{*}{ Cumulative TRISE $\left({ }^{\circ} \mathrm{C}\right)$} & & Median \\
\hline & & 3.51 (IQR 3.09-3.91) \\
\hline & Missing & $23(10.1 \%)$ \\
\hline \multirow[t]{3}{*}{ Cumulative CEM43T90 (min) } & & Median \\
\hline & & 3.31 (IQR $1.90-5.54)$ \\
\hline & Missing & $23(10.1 \%)$ \\
\hline \multirow[t]{2}{*}{ Treatment duration (min) } & & Median \\
\hline & & 89.0 (IQR 88.0-90.0) \\
\hline
\end{tabular}

The effect of thermal dose in patients treated with modern radiotherapy techniques

A subgroup of 66 patients received state-of-the-art radiotherapy, i.e. Image (MRI) guided brachytherapy (IGBT), and IMRT or VMAT (Fig. 1). These IGBT patients treated with modern radiotherapy techniques, showed a significant higher LC and DSS compared to the non-IGBT patients (Fig. 2). A comparison of other characteristics between the IGBT versus the non-IGBT patients is shown in Supplementary Table A. Next, we explored the effect of thermal dose in the patients treated with modern radiotherapy techniques, which were the 66 patients who had received IGBT (Fig. $1+2$ ). There were 9 local recurrences in this patient group. Despite this low number of events, in univariate Cox regression analysis both Histology (HR 0.15; 95\% CI 0.04-0.65) and TRISE (HR 0.33; 95\% CI 0.12-0.96) remained to have a significant effect on LC (Table 3 ).

Analysis of grade 3 or higher late toxicity scores in median TRISE and Time Interval groups

To determine the effect of TRISE, CEM43T90 and IGBT use on toxicity, we analyzed the incidence of grade 3 or higher late toxic- 


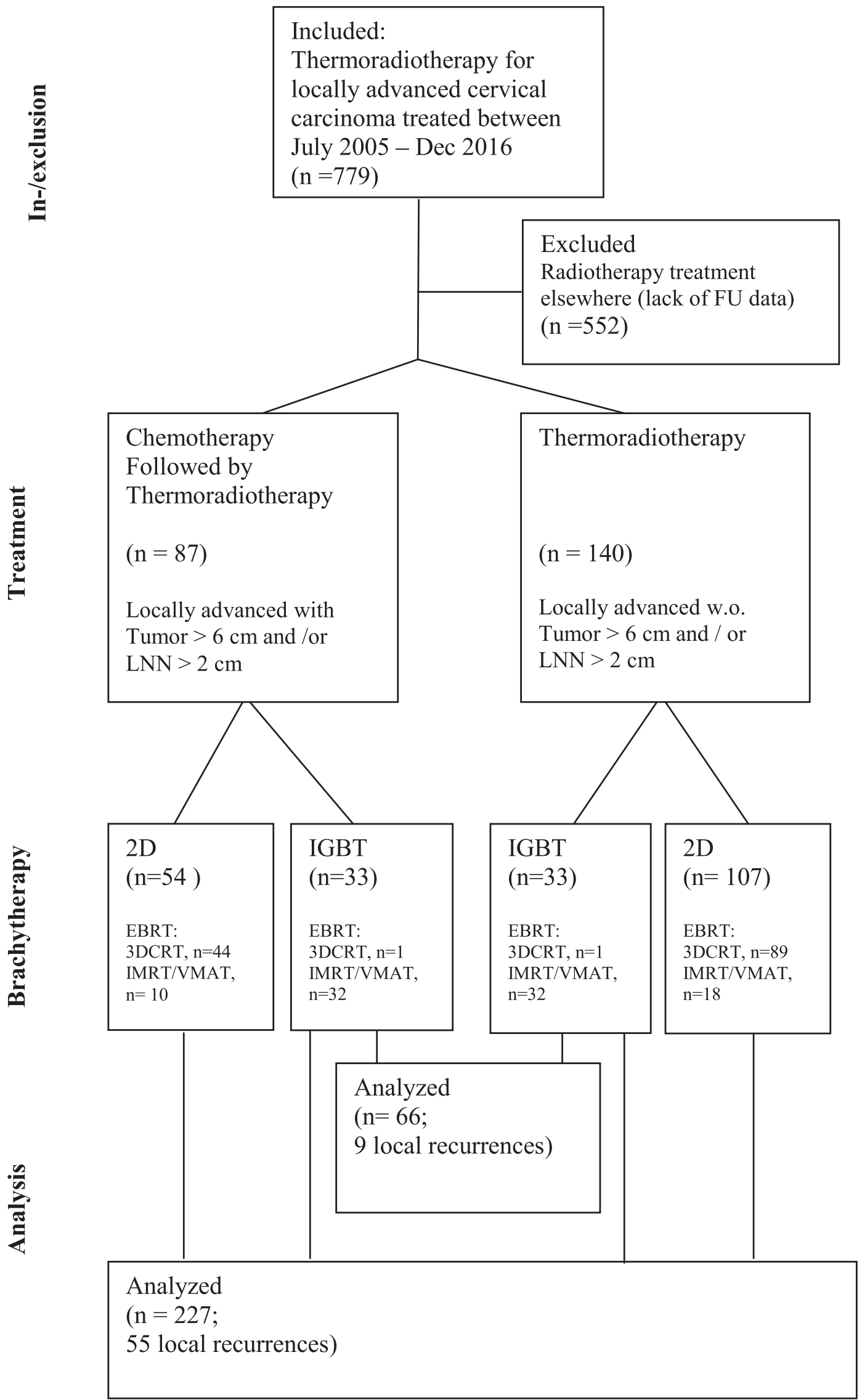

Fig. 1. Consort diagram showing the distribution of patients over treatment protocols and radiotherapy techniques. 
Table 2

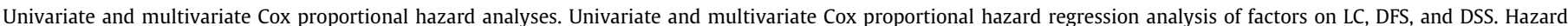

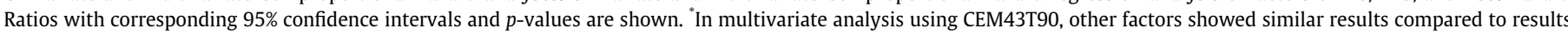
shown here for TRISE.

\begin{tabular}{|c|c|c|c|c|c|c|c|}
\hline & \multirow[t]{2}{*}{ Unit variable increase } & \multicolumn{2}{|l|}{$\mathrm{LC}$} & \multicolumn{2}{|l|}{ DFS } & \multicolumn{2}{|l|}{ DSS } \\
\hline & & $\operatorname{HR}(95 \% \mathrm{CI})$ & $p$-Value & $\mathrm{HR}(95 \% \mathrm{CI})$ & $p$-Value & $\mathrm{HR}(95 \% \mathrm{CI})$ & $p$-Value \\
\hline \multicolumn{8}{|l|}{ Univariate analysis } \\
\hline \multirow[t]{2}{*}{ Age } & Years & $\begin{array}{l}0.99 \\
(0.97-1.00)\end{array}$ & 0.107 & $\begin{array}{l}1.00 \\
(0.99-1.01)\end{array}$ & 0.944 & $\begin{array}{l}1.00 \\
(0.99-1.02)\end{array}$ & 0.765 \\
\hline & & & 0.014 & & 0.007 & & 0.312 \\
\hline \multirow[t]{2}{*}{ Histology } & Squamous vs. adeno & $\begin{array}{l}0.38 \\
(0.20-0.74)\end{array}$ & 0.005 & $\begin{array}{l}0.45 \\
(0.26-0.76)\end{array}$ & 0.003 & $\begin{array}{l}0.64 \\
(0.34-1.18)\end{array}$ & 0.154 \\
\hline & Other vs. adeno & $\begin{array}{l}0.71 \\
(0.23-2.24)\end{array}$ & 0.559 & $\begin{array}{l}0.81 \\
(0.32-2.05)\end{array}$ & 0.650 & $\begin{array}{l}0.89 \\
(0.31-2.51)\end{array}$ & 0.818 \\
\hline \multirow[t]{4}{*}{ FIGO stage } & & & 0.001 & & $<0.001$ & & $<0.001$ \\
\hline & IIA + IIB vs. IB & $\begin{array}{l}1.23 \\
(0.46-3.28)\end{array}$ & 0.675 & $\begin{array}{l}1.33 \\
(0.64-2.74)\end{array}$ & 0.447 & $\begin{array}{l}1.26 \\
(0.55-2.88)\end{array}$ & 0.580 \\
\hline & IIIA + IIIB vs. IB & $\begin{array}{l}3.87 \\
(1.45-10.33)\end{array}$ & 0.007 & $\begin{array}{l}3.34 \\
(1.58-7.06)\end{array}$ & 0.002 & $\begin{array}{l}3.54 \\
(1.53-8.19)\end{array}$ & 0.003 \\
\hline & IVA + IVB vs. IB & $\begin{array}{l}2.78 \\
(0.91-8.50)\end{array}$ & 0.074 & $\begin{array}{l}2.44 \\
(1.03-5.80)\end{array}$ & 0.044 & $\begin{array}{l}3.08 \\
(1.19-7.98)\end{array}$ & 0.020 \\
\hline \multirow[t]{3}{*}{ Lymphadenopathy } & & & 0.076 & & 0.466 & & 0.558 \\
\hline & Iliac vs. negative & $\begin{array}{l}2.02 \\
(1.08-3.76)\end{array}$ & 0.028 & $\begin{array}{l}1.34 \\
(0.84-2.15)\end{array}$ & 0.218 & $\begin{array}{l}1.26 \\
(0.75-2.13)\end{array}$ & 0.386 \\
\hline & PAO vs. negative & $\begin{array}{l}1.30 \\
(0.59-2.90)\end{array}$ & 0.517 & $\begin{array}{l}1.16 \\
(0.65-2.07)\end{array}$ & 0.622 & $\begin{array}{l}1.35 \\
(0.74-2.50)\end{array}$ & 0.332 \\
\hline CEM43T90 & $\min$ & $\begin{array}{l}0.86 \\
(0.76-0.98)\end{array}$ & 0.020 & $\begin{array}{l}0.95 \\
(0.87-1.04)\end{array}$ & 0.250 & $\begin{array}{l}0.98 \\
(0.89-1.07)\end{array}$ & 0.647 \\
\hline TRISE & ${ }^{\circ} \mathrm{C}$ & $\begin{array}{l}0.54 \\
(0.35-0.81)\end{array}$ & 0.003 & $\begin{array}{l}0.75 \\
(0.53-1.06)\end{array}$ & 0.104 & $\begin{array}{l}0.85 \\
(0.58-1.25)\end{array}$ & 0.420 \\
\hline IGBT yes/no & Yes vs. no & $\begin{array}{l}0.46 \\
(0.22-0.95)\end{array}$ & 0.036 & $\begin{array}{l}0.66 \\
(0.39-1.12)\end{array}$ & 0.122 & $\begin{array}{l}0.48 \\
(0.24-0.94)\end{array}$ & 0.033 \\
\hline \multicolumn{8}{|l|}{ Multivariate analysis } \\
\hline & & & 0.009 & & 0.021 & & \\
\hline \multirow[t]{2}{*}{ Histology } & Squamous vs. adeno & $\begin{array}{l}0.33 \\
(0.16-0.69)\end{array}$ & 0.003 & $\begin{array}{l}0.46 \\
(0.25-0.84)\end{array}$ & 0.012 & & n.s. \\
\hline & Other vs. adeno & $\begin{array}{l}0.75 \\
(0.23-2.45)\end{array}$ & 0.628 & $\begin{array}{l}0.89 \\
(0.34-2.36)\end{array}$ & 0.821 & & \\
\hline \multirow[t]{4}{*}{ FIGO stage } & & & 0.013 & & 0.003 & & 0.001 \\
\hline & IIA + IIB vs. IB & $\begin{array}{l}1.91 \\
(0.68-5.35)\end{array}$ & 0.218 & $\begin{array}{l}1.69 \\
(0.76-3.77)\end{array}$ & 0.200 & $\begin{array}{l}1.38 \\
(0.57-3.37)\end{array}$ & 0.477 \\
\hline & IIIA + IIIB vs. IB & $\begin{array}{l}4.04 \\
(1.47-11.14)\end{array}$ & 0.007 & $\begin{array}{l}3.28 \\
(1.47-7.35)\end{array}$ & 0.004 & $\begin{array}{l}3.41 \\
(1.38-8.40)\end{array}$ & 0.008 \\
\hline & IVA + IVB vs. IB & $\begin{array}{l}3.80 \\
(1.20-12.07)\end{array}$ & 0.024 & $\begin{array}{l}3.45 \\
(1.36-8.76)\end{array}$ & 0.009 & $\begin{array}{l}3.62 \\
(1.33-9.86)\end{array}$ & 0.012 \\
\hline \multirow[t]{3}{*}{ Lymphadenopathy } & & & 0.015 & & & & \\
\hline & Iliac vs. negative & $\begin{array}{l}2.75 \\
(1.37-5.53)\end{array}$ & 0.004 & & & & \\
\hline & PAO vs. negative & $\begin{array}{l}1.604 \\
(0.68-3.77)\end{array}$ & 0.278 & & & & \\
\hline TRISE & ${ }^{\circ} \mathrm{C}$ & $\begin{array}{l}0.43 \\
(0.28-0.68)\end{array}$ & $<0.001$ & $\begin{array}{l}0.70 \\
(0.49-1.01)\end{array}$ & 0.054 & & n.s. \\
\hline IGBT yes/no & Yes vs. no & $\begin{array}{l}0.40 \\
(0.19-0.84)\end{array}$ & 0.016 & $\begin{array}{l}0.63 \\
(0.37-1.08)\end{array}$ & 0.094 & $\begin{array}{l}0.44 \\
(0.22-0.88)\end{array}$ & 0.020 \\
\hline CEM43T90* & $\min$ & $\begin{array}{l}0.83 \\
(0.72-0.96)\end{array}$ & 0.010 & & n.s. & & n.s. \\
\hline
\end{tabular}

ities. There was no significant difference in the incidence of toxicity in patients with lower or higher than the median TRISE (11.8\% versus $10.8 \%$, respectively, $p=0.825)$, lower or higher than the median CEM43T90 (14.7\% versus 7.8\%, respectively, $p=0.121$ ) and patients receiving IGBT or not ( $7.6 \%$ versus $12.4 \%$, respectively, $p=0.289$ ) (Table 4).

\section{Discussion}

The results of this study confirm the conclusions of our previous cohort study, in which we showed a dose dependent effect of the thermal dose parameters CEM43T90 and TRISE on LC and DSS [11]. In the current, more recent cohort, TRISE and CEMT90 remained to have a significant effect on LC in univariate analysis. An exploratory univariate analysis also showed a significant effect of known predictive factors on LC. In multivariate analysis, TRISE and CEM43T90 had an independent effect on LC. Based upon the results of this study, we conclude that thermal dose is an important parameter to optimize as it is remains predictive for LC in patients treated with state-of-the-art radiotherapy.

Local control (LC) is an essential condition for definitive cure and subsequent patient survival [17]. Other retrospective cohort studies have found similar associations between thermal dose and LC for various tumor types in smaller cohorts [29-34], though some failed to demonstrate such an effect [35]. For this reason, attempts have been made to introduce prospective prescription of thermal dose [36-38]. Jones et al demonstrated that a prescription of $>10$ CEM43T90 of hyperthermia results in increased LC in patients with varying histology [36]. The most appropriate thermal dose parameter to optimize may depend on tumor type, but is probably more influenced by hyperthermia technique and tumor location. For example, in superficial hyperthermia interstitial ther- 

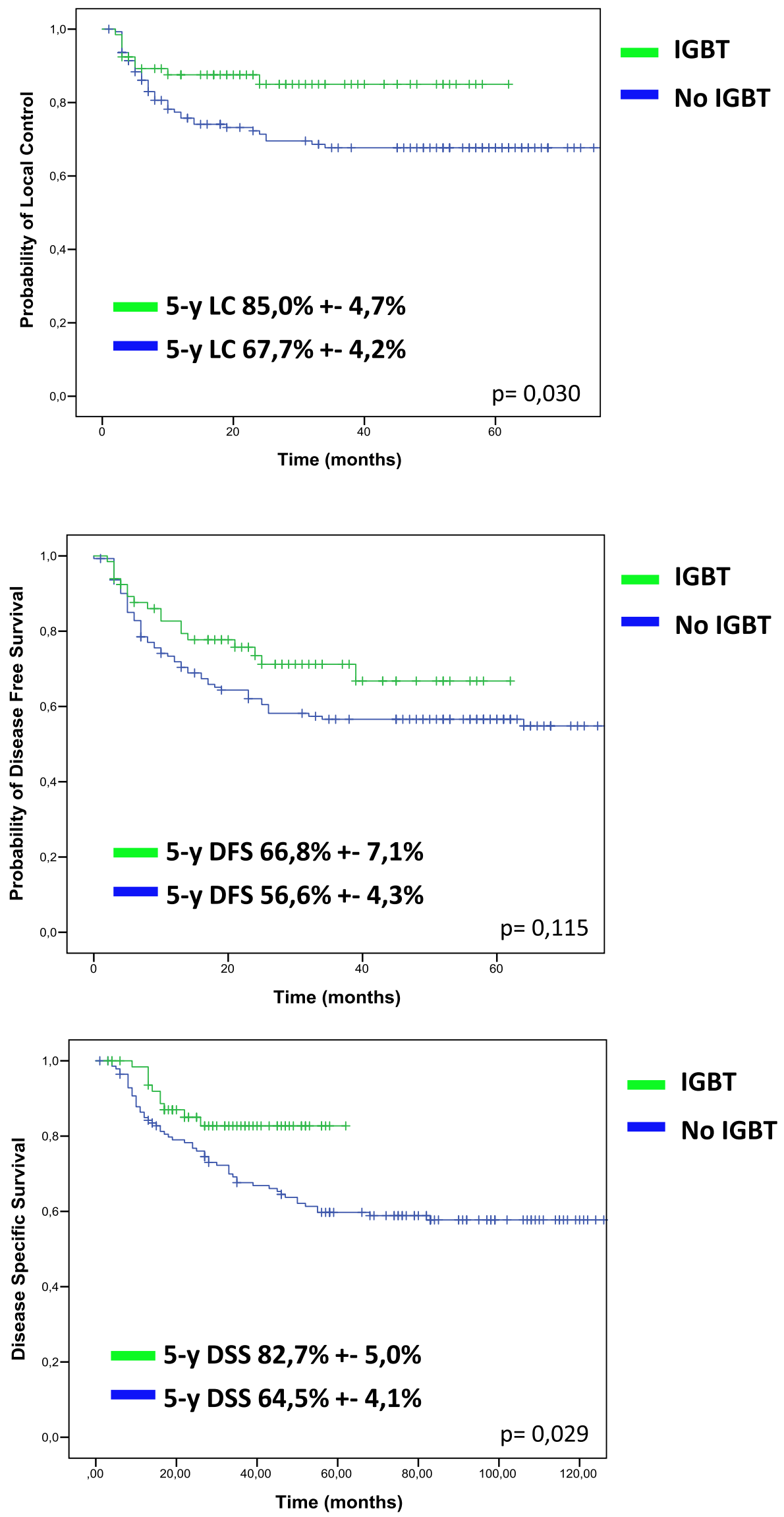

Fig. 2. KM analysis of the effect of the introduction of IGBT. KM curves for LC, DFS and DSS are shown and groups were compared (log-rank test). 
Table 3

Univariate Cox proportional hazard analysis in IGBT patients. Univariate Cox proportional hazard regression analysis of factors on LC. Hazard Ratios with corresponding 95\% confidence intervals and p-Values are shown.

\begin{tabular}{|c|c|c|c|}
\hline & \multirow[t]{2}{*}{ Unit variable increase } & \multicolumn{2}{|l|}{ LC } \\
\hline & & $\operatorname{HR}(95 \% \mathrm{CI})$ & $p$-Value \\
\hline \multirow[t]{3}{*}{ Histology } & & & 0.031 \\
\hline & Squamous vs. adeno & $\begin{array}{l}0.15 \\
(0.04-0.65)\end{array}$ & 0.011 \\
\hline & Other vs. adeno & $\begin{array}{l}0.61 \\
(0.06-5.94)\end{array}$ & 0.674 \\
\hline \multirow[t]{4}{*}{ FIGO stage } & & & 0.828 \\
\hline & IIA + IIB vs. IB & $\begin{array}{l}0.86 \\
(0.10-7.38)\end{array}$ & 0.891 \\
\hline & IIIA + IIIB vs. IB & $\begin{array}{l}1.713 \\
(0.18-16.51)\end{array}$ & 0.641 \\
\hline & IVA + IVB vs. IB & & 0.985 \\
\hline \multirow[t]{3}{*}{ Lymphadenopathy } & & & 0.811 \\
\hline & Iliac vs. negative & $\begin{array}{l}1.51 \\
(0.30-7.49)\end{array}$ & 0.618 \\
\hline & PAO vs. negative & $\begin{array}{l}0.88 \\
(0.08-9.70)\end{array}$ & 0.915 \\
\hline CEM43Т90 & $\min$ & $\begin{array}{l}0.77 \\
(0.53-1.11)\end{array}$ & 0.157 \\
\hline TRISE & ${ }^{\circ} \mathrm{C}$ & $\begin{array}{l}0.34 \\
(0.12-0.96)\end{array}$ & 0.042 \\
\hline CTVHR dose & Gray & $\begin{array}{l}0.99 \\
(0.91-1.06)\end{array}$ & 0.707 \\
\hline
\end{tabular}

mometry is the standard, while it is hardly ever possible for deep seated tumors, thereby influencing the most appropriate thermal dose parameter. Moreover, the CEM concept was derived from the impact of thermal dose on direct cell kill and does not necessarily capture the multifactorial effects of hyperthermia [39-41]. As TRISE is more robust, it may capture these multifactorial effects better, at least for deep seated tumors. In the current cohort of cervical carcinoma patients, TRISE remains more predictive for outcome than CEM43T90 (Table 2), but verification for other deep seated tumors is warranted.

Importantly, in patients treated with IGBT, an exploratory analysis showed there was still an effect of TRISE on LC in univariate Cox analysis (Table 3). The relevance of a high thermal dose is further illustrated in an exploratory Kaplan-Meier analysis for the 5-y LC, DFS and DSS in patients with a higher than median TRISE and a higher than median CTVHR (i.e. radiation) dose $(n=17)$ versus patients having a lower than median TRISE and/or a lower than median CTVHR dose $(n=49)$. In the high TRISE/high CTVHR dose patients, the 5 -y DFS was $100 \%$, which differed significantly to the DFS in patients with a low TRISE and/or low CTVHR dose (Fig. 3). Although definitive confirmation of a thermal dose effect relationship for state-of-the-art radiotherapy is required in a larger patient population, this finding suggests that hyperthermia also enhances radiotherapy in cervical carcinoma patients treated with a more conformal and higher dose to the tumor area.

Thermal dose has also been associated with increased late toxicity, for example skin damage in a retrospective cohort study of 262 recurrent breast cancers [42]. In our cohort, we did not observe differences in late severe toxicity between high or low thermal dose groups. Also, the introduction of IGBT did not significantly increase late toxicity. These results of our current study are in line with the results from the Dutch Deep Hyperthermia trial and our previous cohort, both demonstrating no added late toxicity of deep hyperthermia in the pelvic region $[3,6,8,11]$. Similarly, others have found that the use of IGBT has not resulted in higher late toxicity rates $[17,43]$.

The confirmation of a thermal dose effect on clinical outcome suggests that further enhancement of the quality of the hyperthermia treatment potentially leads to further clinical improvement. A higher thermal dose can be achieved through an increase in temperature (i.e. improved spatial control of the energy deposition), longer treatment times or addition of hyperthermia treatments. By use of hyperthermia planning we aimed to increase temperatures in the target area [21]. MRI-guided hyperthermia could potentially lead to higher temperatures in the target areas in the future. MRI is a useful tool to improve the optimization algorithm by improved understanding of hotspot development and aid of applicator design [44]. Finally, another approach is to better exploit the biological mechanisms of hyperthermia using novel sensitizers $[40,45]$.

Comparing the outcome results of the current cohort to previous results, the 5-year LC in our current cohort was $72.7 \%$, compared to $61.0 \%$ in the thermoradiotherapy arm of the Dutch Deep Hyperthermia Trial and to $53.0 \%$ in our previous cohort $[3,11]$. The 5-year DSS in the current cohort was also higher, i.e. 62.9\%, compared to $47.0 \%$ in our previous cohort of cervical cancer patients [11]. These marked differences between our current cohort and the previous cohort in LC and DSS can be explained by improvements in radiotherapy techniques. Additionally, improvements in hyperthermia delivery and quality, may also contribute to the improved outcomes observed. All of these factors may play a role, but a clear benefit of IGBT has been demonstrated in literature in terms of improved LC and OS [15-18].

In conclusion, this study confirms our earlier reported relationship between thermal dose and clinical outcome in patients with cervical cancer, also in patients treated with modern radiotherapy

Table 4

Analysis of Grade 3 or higher late toxicity. Incidence of grade 3 or higher late toxicity in various patient groups was analyzed. $p$-Values are shown.

\begin{tabular}{|c|c|c|c|}
\hline & Low TRISE & High TRISE & $p$-Value \\
\hline & & & 0.825 \\
\hline No grade 3 or higher toxicity & $91(89.2 \%)$ & $90(88.2 \%)$ & \\
\hline Grade 3 or higher toxicity & $11(10.8 \%)$ & $12(11.8 \%)$ & \\
\hline \multirow[t]{3}{*}{ Total } & $102(100 \%)$ & $102(100 \%)$ & \\
\hline & Low CEM43T90 & High CEM43T90 & $p$-Value \\
\hline & & & 0.121 \\
\hline No grade 3 or higher toxicity & $94(92.2 \%)$ & $87(85.3 \%)$ & \\
\hline Grade 3 or higher toxicity & $8(7.8 \%)$ & $15(14.7 \%)$ & \\
\hline \multirow[t]{3}{*}{ Total } & $102(100 \%)$ & $102(100 \%)$ & \\
\hline & No IGBT & IGBT & $p$-Value \\
\hline & & & 0.289 \\
\hline No grade 3 or higher toxicity & $141(87.6 \%)$ & $61(92.4 \%)$ & \\
\hline Grade 3 or higher toxicity & $20(12.4 \%)$ & $5(7.6 \%)$ & \\
\hline Total & $161(100 \%)$ & $66(100 \%)$ & \\
\hline
\end{tabular}




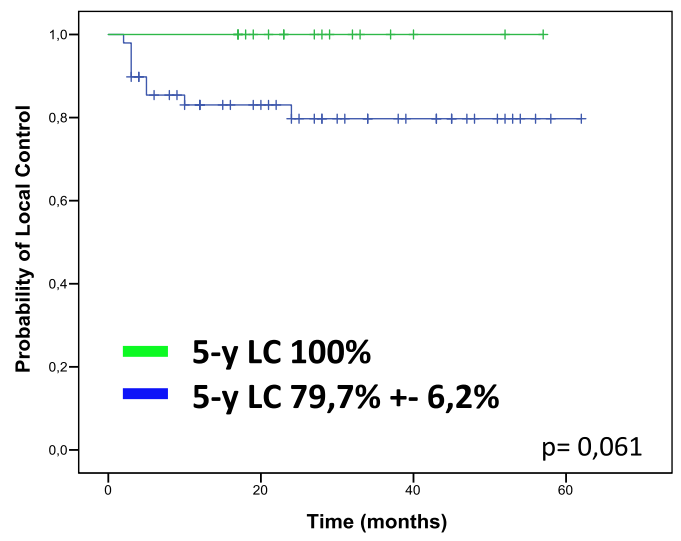

\section{High CTVHR / high TRISE \\ Low CTVHR and /or low TRISE}
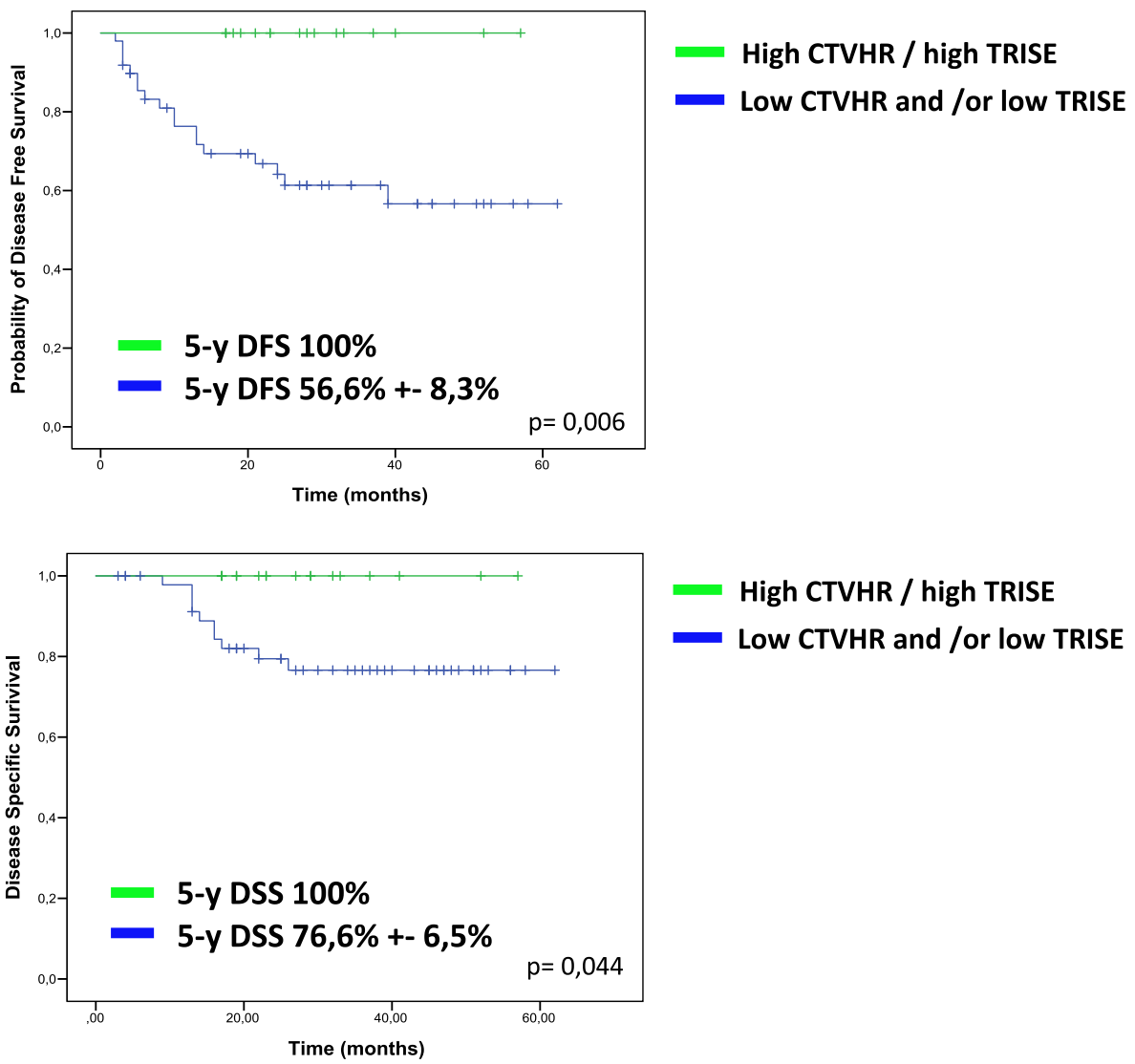

High CTVHR / high TRISE

Low CTVHR and /or low TRISE

Fig. 3. KM analysis of the combined effect of thermal and radiotherapy dose in patients treated with IGBT. KM curves for LC, DFS and DSS are shown and groups were compared (log-rank test)

techniques. This is a strong encouragement to continue our efforts to improve the quality of the hyperthermia treatment as this effort could translate directly into improved clinical outcome.

\section{Appendix A. Supplementary data}

Supplementary data to this article can be found online at https://doi.org/10.1016/j.radonc.2019.06.021.

\section{References}

[1] Ferlay J et al. Cancer incidence and mortality worldwide: sources, methods and major patterns in GLOBOCAN 2012. Int J Cancer 2015;136:E359-86.

[2] Chemoradiotherapy for Cervical Cancer Meta-Analysis, C.. Reducing uncertainties about the effects of chemoradiotherapy for cervical cancer: systematic review and meta-analysis of individual patient data from 18 randomized trials. J Clin Oncol 2008;26:5802-12.

[3] Franckena $M$ et al. Long-term improvement in treatment outcome after radiotherapy and hyperthermia in locoregionally advanced cervix cancer: an update of the Dutch Deep Hyperthermia Trial. Int J Radiat Oncol Biol Phys 2008;70:1176-82.

[4] Lutgens L et al. Combined use of hyperthermia and radiation therapy for treating locally advanced cervical carcinoma. Cochrane Database Syst Rev 2010;1:CD006377.

[5] https://www.oncoline.nl/cervixcarcinoom Dutch Association of Comprehensive Cancer Centers.

[6] Franckena $\mathrm{M}$ et al. Radiotherapy and hyperthermia for treatment of primary locally advanced cervix cancer: results in 378 patients. Int J Radiat Oncol Biol Phys 2009;73:242-50.

[7] https://www.accessdata.fda.gov/scripts/cdrh/cfdocs/cfhde/hde.cfm?id= H090002.

[8] van der Zee J et al. Comparison of radiotherapy alone with radiotherapy plus hyperthermia in locally advanced pelvic tumours: a prospective, randomised, multicentre trial. Dutch Deep Hyperthermia Group. Lancet 2000;355:1119-25. 
[9] van der Zee J et al. The Kadota Fund International Forum 2004-clinical group consensus. Int J Hyperthermia 2008;24:111-22.

[10] Datta NR et al. Local hyperthermia combined with radiotherapy and-/or chemotherapy: recent advances and promises for the future. Cancer Treat Rev 2015;41:742-53.

[11] Franckena M et al. Hyperthermia dose-effect relationship in 420 patients with cervical cancer treated with combined radiotherapy and hyperthermia. Eur J Cancer 2009;45:1969-78.

[12] Sapareto SA, Dewey WC. Thermal dose determination in cancer therapy. Int J Radiat Oncol Biol Phys 1984;10:787-800.

[13] Heijkoop ST et al. Clinical implementation of an online adaptive plan-of-theday protocol for nonrigid motion management in locally advanced cervical cancer IMRT. Int J Radiat Oncol Biol Phys 2014;90:673-9.

[14] Sharfo AW et al. Validation of fully automated VMAT plan generation for library-based plan-of-the-day cervical cancer radiotherapy. PLoS One 2016;11:e0169202.

[15] Tanderup K et al. Effect of tumor dose, volume and overall treatment time on local control after radiochemotherapy including MRI guided brachytherapy of locally advanced cervical cancer. Radiother Oncol 2016;120:441-6.

[16] Lindegaard JC et al. MRI-guided adaptive radiotherapy in locally advanced cervical cancer from a Nordic perspective. Acta Oncol 2013;52:1510-9.

[17] Sturdza A et al. Image guided brachytherapy in locally advanced cervical cancer: improved pelvic control and survival in RetroEMBRACE, a multicenter cohort study. Radiother Oncol 2016;120:428-33.

[18] Potter R et al. Clinical impact of MRI assisted dose volume adaptation and dose escalation in brachytherapy of locally advanced cervix cancer. Radiother Oncol 2007;83:148-55.

[19] Ribeiro I et al. Long term experience with 3D image guided brachytherapy and clinical outcome in cervical cancer patients. Radiother Oncol 2016;120:447-54

[20] Potter $\mathrm{R}$ et al. Present status and future of high-precision image guided adaptive brachytherapy for cervix carcinoma. Acta Oncol 2008;47:1325-36.

[21] Canters RA et al. Implementation of treatment planning in the routine clinical procedure of regional hyperthermia treatment of cervical cancer: an overview and the Rotterdam experience. Int J Hyperthermia 2012;28:570-81.

[22] Franckena $M$ et al. Clinical implementation of hyperthermia treatment planning guided steering: a cross over trial to assess its current contribution to treatment quality. Int J Hyperthermia 2010;26:145-57.

[23] Heijkoop ST et al. Neoadjuvant chemotherapy followed by radiotherapy and concurrent hyperthermia in patients with advanced-stage cervical cancer: a retrospective study. Int J Hyperthermia 2012;28:554-61.

[24] Bruggmoser G et al. Quality assurance for clinical studies in regional deep hyperthermia. Strahlenther Onkol 2011;187:605-10.

[25] Bruggmoser G et al. Guideline for the clinical application, documentation and analysis of clinical studies for regional deep hyperthermia: quality management in regional deep hyperthermia. Strahlenther Onkol 2012;188 (Suppl 2):198-211.

[26] https://www.eortc.be/services/doc/ctc/.

[27] Fatehi D et al. RHyThM, a tool for analysis of PDOS formatted hyperthermia treatment data generated by the BSD2000/3D system. Int J Hyperthermia 2006;22:173-84.
[28] Fatehi D et al. Comparison of intratumor and intraluminal temperatures during locoregional deep hyperthermia of pelvic tumors. Strahlenther Onkol 2007; 183:479-86

[29] Dinges S et al. Combined treatment of inoperable carcinomas of the uterine cervix with radiotherapy and regional hyperthermia. Results of a phase II trial. Strahlenther Onkol 1998;174:517-21.

[30] Oleson JR et al. Sensitivity of hyperthermia trial outcomes to temperature and time: implications for thermal goals of treatment. Int J Radiat Oncol Biol Phys 1993:25:289-97.

[31] Overgaard $\mathrm{J}$ et al. Hyperthermia as an adjuvant to radiation therapy of recurrent or metastatic malignant melanoma. A multicentre randomized trial by the European Society for Hyperthermic Oncology. Int J Hyperthermia 1996;12:3-20.

[32] Wust P et al. Local hyperthermia of N2/N3 cervical lymph node metastases: correlation of technical/thermal parameters and response. Int J Radiat Oncol Biol Phys 1996;34:635-46.

[33] Leopold KA et al. Cumulative minutes with T90 greater than Tempindex is predictive of response of superficial malignancies to hyperthermia and radiation. Int J Radiat Oncol Biol Phys 1993;25:841-7.

[34] Rau B et al. Preoperative radiochemotherapy in locally advanced or recurrent rectal cancer: regional radiofrequency hyperthermia correlates with clinical parameters. Int J Radiat Oncol Biol Phys 2000;48:381-91.

[35] de Bruijne $M$ et al. Evaluation of CEM43 degrees CT90 thermal dose in superficial hyperthermia: a retrospective analysis. Strahlenther Onkol 2010;186:436-43.

[36] Jones EL et al. Randomized trial of hyperthermia and radiation for superficial tumors. J Clin Oncol 2005;23:3079-85.

[37] Maguire PD et al. A phase II trial testing the thermal dose parameter CEM43 degrees T90 as a predictor of response in soft tissue sarcomas treated with preoperative thermoradiotherapy. Int J Hyperthermia 2001;17:283-90.

[38] Thrall DE et al. Thermal dose is related to duration of local control in canine sarcomas treated with thermoradiotherapy. Clin Cancer Res 2005;11:5206-14.

[39] van Rhoon GC. Is CEM43 still a relevant thermal dose parameter for hyperthermia treatment monitoring? Int J Hyperthermia 2016;32:50-62.

[40] van den Tempel N, Horsman MR, Kanaar R. Improving efficacy of hyperthermia in oncology by exploiting biological mechanisms. Int J Hyperthermia 2016;32:446-54.

[41] Dewhirst MW et al. Re-setting the biologic rationale for thermal therapy. Int ] Hyperthermia 2005;21:779-90.

[42] Bakker A et al. Thermal skin damage during reirradiation and hyperthermia is time-temperature dependent. Int J Radiat Oncol Biol Phys 2017;98:392-9.

[43] Fokdal L et al. Image guided adaptive brachytherapy with combined intracavitary and interstitial technique improves the therapeutic ratio in locally advanced cervical cancer: Analysis from the retroEMBRACE study. Radiother Oncol 2016;120:434-40.

[44] van Rhoon GC et al. Hyperthermia by electromagnetic fields to enhanced clinical results in oncology. Conf Proc IEEE Eng Med Biol Soc 2016;2016:359-62.

[45] Vriend LEM et al. Boosting the effects of hyperthermia-based anticancer treatments by HSP90 inhibition. Oncotarget 2017;8:97490-503. 